\title{
Editorial: The death of lifestage?
}

Throughout my experience as a database marketer the gold standard customer attributes when seen from the viewpoint of discrimination have been lifestage and affluence.

Some seven years ago or more my then company, Berry Consulting, launched, with NOP, a product called FRuitS which relied on segmenting consumers for the financial services market; we sold it to several banks and insurance companies and I was even interviewed on a Panorama programme, and asked to provide a moral justification for creating a product that was so powerful that banks would be able in the future to refuse to deal with less valuable customer groups. Within financial services circles however FRuitS was enthusiastically received but no-one questioned the core assumption that the dimensions of lifestage and affluence on which it was built were the best-known means of segmenting people.

More recently I have worked on segmentations for the beer and soft drinks market and in each case the same dimensions were successfully employed. In the case of soft drinks we even discovered that the drink that was fashionable in a person's teens stays with one for life; so watch out for 40 somethings clinging to their Diet Coke cans.

But something very significant has changed all this and the old assumptions have to be re-examined.

That change had occurred was recently bought to my attention by the work of
Professor Ross Honeywill in Australia. He discovered groups whose behaviour was polarised, but whose lifestages were not, and he called them I-Cons and Traditionals. The I-Cons for instance 'insist on individuality, use technology to accelerate slow time, have a sense of style that fuels their spending' whereas the Traditionalists 'have a highly developed sense of group or community, are rule takers rather than rule makers, interested in functionality ahead of design'. Fortunately, the two groups behave very differently in consumer markets and therefore they can be identified.

The I-Cons use phone banking five times more often, buy twice as many books, and drink four times more premium and super premium wine. They are without question a different segment to Traditionals and must be identified as such. Part of Professor Honeywill's thesis is also that an I-Con will behave differently to a Traditionalist in virtually any market he finds himself in.

My recent work in the credit card market has also reinforced this point; spenders who roll their balances are the most valuable customers a credit card company can find, but mysteriously they need not be more or less affluent, or belong to a different life stage, than those who do not. They just behave differently.

So what has changed? My belief is that behaviour and lifestage have finally unentwined themselves. Fathers who start new families in their 50s and 60s, 
students who use their loans to play the stock market and entrepreneurs prepared to borrow in their 70s are all examples of this. A combination of near universal affluence (in the developed world), widespread further education and enabling technology have helped unshackle us from the stereotypic 'seven ages of man'.

So how should database marketers respond to this new challenge?

We would suggest by starting with consumer behaviour itself, rather than a conjecture as to what attributes may be driving it, and then forming any segmentation on the basis of that; for banks and card relationship companies this is relatively straightforward, but in many industries with weak or non-existent transactional behaviour data such as motor cars or insurance, and in call centres dealing with unknown enquirers, this may have to be on the basis of research data rather than recorded transactions on the database; but we should not be deterred.

A behavioural segmentation can then be built, and its motivational and attitudinal drivers probed through the use of further research. But this insightful approach still leaves us without an attributed enquirer or customer unless the initial transactions that drove the segmentation were obtained from the database itself.

Attribution models will only be as powerful as the data that fuel them, and we appear to be ruling out the traditional lifestage variable king for that job. In its place we are going to have to substitute something softer, something that enlightens us about the motivations and attitudes of individual consumers, and on the conventional database that does not exist.

There are, however, options; we can test whether the lifestyle companies' data can give us discrimination, and we can start collecting answers to individual questions that could be embedded in application forms, and asked in call centres and on websites.

Do not be deterred when applying for your next credit card if you are asked whether 'you lie awake at night worrying about how you are going to pay off the balance' and get given a higher credit limit if you do; it just could turn out to be more important than your marital status, or the number of children under 18 living in your household.
JULIAN BERRY

Sophron Partners Ltd April, 2002 